\title{
Editorial
}

\section{Sri Lanka Journal of Sexual Health and HIV Medicine}

\author{
(Sri Lanka JoSHH)
}

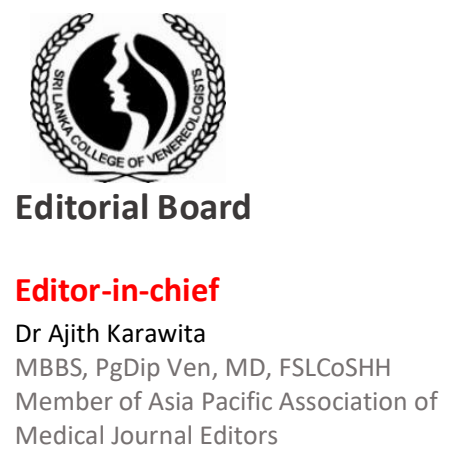

Acquisition editor

Dr HACW Hathurusinghe MBBS, PgDip Ven, MD

\section{Assistant editors}

Dr Nalaka Abeygunasekara

MBBS, PgDip Ven, MD

Dr Manjula Rajapakse MBBS, PgDip Ven, MD

Dr Darshani Mallikarachchi MBBS, PgDip Ven, MD, DFSRH (UK)

Editorial board members

Dr Ariyaratne Manathunge MBBS, MSC, MD, FSLCV

Prof Sampatha Goonewardena MBBS, MSc, MD

Dr Jayadarie Ranatunga

MBBS, DFM, PgDip Ven, MD

Dr Gayani Nanayakkara

MBBS, PgDip Ven, MD

Dr Prageeth Premadasa

MBBS, PgDip Ven, MD, DFSRH (UK),

Dip in Psychosexual Medicine, FECSM

\section{Secretary}

Dr Rahal Fernando

MBBS, PgDip Ven, MD
Sri Lanka College of Sexual Health and HIV Medicine (CoSHH) proudly publishes the latest volume of the Sri Lanka Journal of Sexual Health and HIV Medicine (Sri Lanka JoSHH) in both electronic and print media.

Presidential address at the inaugural session of the "Sri Lanka CoSHH conference 2018" is the leading article of the journal titling "Reaching the unreached in STI and HIV" which encompass all public health efforts to control STI and HIV in Sri Lanka with current and future prospects. Reaching and delivering health services to needy people is challenging when stigma is attached with a disease. Therefore, reaching needs to be applied for different key populations and vulnerable populations in an appropriate way to cover the specific population groups, hidden networks and different geographical areas. Furthermore, reaching is not everything unless it is coupled with effective prevention package which include repeated exposure to behaviour change communications and availability of biological means of prevention.

The next biggest highlight of this volume is the congratulations received by WHO for eliminating mother to child transmission of HIV and syphilis in Sri Lanka, which is a landmark victory in the history of STI and HIV control in the country. Sri Lanka is the third country in WHO South-East-Asia Region to achieve this after Thailand, and Maldives. This is the latest public health achievement by the country. Earlier, Sri Lanka achieved the victory over polio, neonatal tetanus, malaria, measles, rubella and lymphatic filariasis. This demonstrate the country's leadership and commitment to the public health through multi-partnered, multi-sectoral, and multi-level concerted efforts. Achieving the elimination status is not the end, but the beginning of a new look to strengthen and maintain the victory.

\section{Dr Ajith Karawita}

Honorary fellow and the past president (2015-2016) of CoSHH

(D) https://orcid.org/0000-0003-2956-8479

\section{Editor-in-chief}

